\title{
Resolução e formulação de problemas no desenvolvimento do raciocínio combinatório
}

Célia Barros Nunes

Thaylan Campeche Vidal

\section{Resumo}

A presente pesquisa, de natureza qualitativa, buscou explicitar os benefícios da utilização da Metodologia de Ensino-aprendizagem-avaliação de Matemática através da Resolução de Problemas para estudantes de um curso de Licenciatura em Matemática, por meio de um minicurso que visou proporcionar um ambiente de aprendizagem onde a pesquisa pudesse ser elaborada. Os dados coletados evidenciaram que, além de cultivar uma cultura de sala de aula na qual os alunos assumem papéis ativos e construtivos, a partir do contexto proporcionado, eles se apropriaram dos conceitos elementares da Análise Combinatória, alcançando generalizações que partiam da sua própria compreensão, e não do texto de um livro didático. Pode-se observar que a Formulação de Problemas, quando integrada à Resolução de Problemas, tornou-se um potencializador do processo de aprendizagem, no qual se estimulava à assimilação dos conteúdos e as habilidades de resolução de problemas motivada pela criatividade dos participantes. Por fim, fica evidente a forma com a qual a perspectiva de aprendizagem, orientada por metodologias diferenciadas, é imprescindível no ambiente de preparação docente, já que estes futuros professores adotam uma visão que objetiva levar aquilo que experimentam no desenvolver do curso à suas futuras salas de aula.

Palavras chaves: Análise Combinatória, Resolução de Problemas, Matemática Discreta. 


\title{
Problem solving and formulating in the development of the combinatorial thinking
}

Célia Barros Nunes

Thaylan Campeche Vidal

\begin{abstract}
The present research, of qualitative nature, sought to explicit the benefits consequent to the use of the methodology of Math teaching-learningevaluation through Problem Solving for students of the UNEB - Campus X mathematics degree, through a brief course that aimed to provide a learning environment where the research could be performed. The data collected evidenced that, besides nurturing a classroom culture in which the students take on active and constructive roles, through the context provided, they took ownership of the Combinatorial Analysis elementary concepts, reaching generalizations that originated from the students' comprehension, and not from the wording of a textbook. It can be observed that problem formulation, when integrated to problem solving, became a propelling tool to the learning process, where the subject assimilation and the problem-solving skills were stimulated by the participants' creativity. Lastly, it becomes evident the way in which the perspective of learning oriented by distinctive methodologies is indispensable in a teacher preparing environment, since those future teachers take on a vision that intents to take that which is experienced in the development of the course to their future classrooms.
\end{abstract}

Key words: Combinatorial Analysis, Discrete Mathematics, Problem Solving. 


\section{Introdução}

A Análise Combinatória é um dos ramos da Matemática que mais dificuldades apresentam para os alunos no Ensino Médio. Saber apenas fórmulas de arranjo, combinação, etc. não é suficiente. O que se deve priorizar neste assunto é o raciocínio. Sua importância deve-se ao fato de ele modelar uma situação na qual há várias possibilidades de construção de agrupamentos, de caminhos, fornecendo um tipo específico de interpretação quando se devem considerar os resultados possíveis para cada um desses agrupamentos ou caminhos (MENEGHETI \& DUTRA, 2012).

Dado que os problemas de Análise Combinatória são variados e por vezes complexos apresentando, muitas vezes, grandes dificuldades para os alunos - pois nem sempre o caminho a ser tomado para chegar à solução está claro - Borba (2010) salienta que é preciso examinar e verificar a natureza do tipo do problema e quais estratégias podem ser utilizadas num caso específico, sendo também possível fazer um levantamento de possibilidades e analisá-las. Neste contexto, a dificuldade encontra-se na conexão adequada entre o problema e a teoria matemática correspondente.

Deste modo, segundo Souza (2010), o desenvolvimento do raciocínio combinatório requer muito mais do que apenas classificar os problemas em Permutação, Arranjo ou Combinação. Menegheti \& Dutra (2012) afirmam que os métodos referentes à Análise Combinatória devem ser compreendidos pelos alunos de maneira que os conceitos envolvidos sejam por eles construídos, enfatizando o processo de aprendizagem, e não seu produto final.

Neste sentido, a Metodologia de Ensino-aprendizagem-avaliação de Matemática através da Resolução de Problemas apresenta-se como um caminho para ensinar e aprender a Análise Combinatória, devido a sua forma de implementação no contexto da sala de aula, onde o aluno tem a liberdade de se expressar e criar, não somente objetivando o saber exposto pelo professor, mas buscando o conhecimento para si, uma vez que se sente estimulado a obtê-lo. O professor neste contexto assume o papel de mediador, ou seja, cabe a ele mediar o conhecimento adquirido pelo aluno de modo a formalizá-lo em um saber matemático, reconhecendo que a compreensão daquilo que o ensino da Matemática objetiva é de natureza individual, e, portanto, o entendimento não é algo que se possa transferir de professor para aluno.

Com base nestas premissas iniciais, o presente artigo tem por finalidade explicitar os benefícios consequentes da utilização da Metodologia de Ensino-aprendizagem-avaliação de Matemática através da Resolução de Problemas para estudantes de um curso de Licenciatura em Matemática no que se trata da Análise Combinatória, em forma de um minicurso. Em complemento a esta metodologia, o artigo também enfoca a formulação de problemas como 
uma atividade criativa e investigativa e que pode estimular o interesse dos alunos pela Matemática.

\section{Análise Combinatória x Resolução de Problemas}

A Análise Combinatória tem um papel importante na Matemática escolar, seja no desenvolvimento da ideia de probabilidade, seja no potencial de estimular a capacidade de abstração do estudante para resolver problemas. Através dela é possível:

[...]desenvolver atividades contextualizadas socioculturalmente, aproximando-o da realidade, permitindo vivenciar situações próximas, que lhe possibilitam reconhecer a diversidade a qual o cerca e reconhecer-se como indivíduo capaz de ler e atuar nesta realidade, competência proposta pelo $\mathrm{PCN}_{+}$, Ensino Médio (GROENWALD, ZOCH \& HOMA, 2009, p. 33)

Acrescentam os autores que a Análise Combinatória é a parte da Matemática que estuda e desenvolve métodos para a resolução de problemas que envolvem contagem ou existência, exigindo, quase sempre, engenhosidade e a compreensão plena da situação descrita pelo problema. De uma maneira geral, pode-se dizer que é a parte da Matemática que analisa estruturas e relações discretas. Tais relações se configuram em um importante ramo da matemática contemporânea chamado Matemática Discreta.

Os Principles and Standards for School Mathematics (NCTM, 2000, p. 31), ao discutirem o currículo de Matemática, destacam a Matemática Discreta como "um ramo ativo da Matemática contemporânea que é amplamente utilizado em negócios e indústrias". Reforça este documento que a Matemática Discreta deve ser uma parte integrante do currículo da matemática escolar, cujos conteúdos emergem, naturalmente, ao longo de outras vertentes da Matemática. Seu foco está em determinar uma contagem, além de contemplar três outros importantes tópicos matemáticos: análise combinatória, iteração e recorrência, e grafos.

A Análise Combinatória pode ser caracterizada como "a matemática da contagem sistemática” (NCTM, 2000, p. 31). Nela, realizam-se os estudos em torno do processo de contagem, partindo de princípios simples e expandindo-os em algoritmos em um processo complexo. Algoritmos estes que permitem simplificar o processo árduo de contagem e listagem de conjuntos com quantidades abundantes de elementos. A Contagem, ao mesmo tempo em que possibilita uma abordagem mais completa da probabilidade por si só, permite também o desenvolvimento de uma nova forma de pensar em Matemática denominada raciocínio combinatório. Ou seja, decidir sobre a forma mais adequada de organizar números ou informações para poder contar os casos possíveis não deve ser aprendido como uma lista 
de fórmulas, mas como um processo que exige a construção de um modelo simplificado e explicativo da situação (BRASIL, 2002, p. 126).

A importância do raciocínio combinatório deve-se ao fato de ele modelar uma situação na qual há várias possibilidades de construção de agrupamentos, de caminhos, fornecendo um tipo específico de interpretação quando se devem considerar os resultados possíveis para cada um desses agrupamentos ou caminhos.

Albuquerque, Veloso, Rocha, Santos, Serrazina e Napóles (2010) enfatizam que a Análise Combinatória é um ramo da Matemática que estuda coleções finitas de objetos nomeadamente no que diz respeito a contagem e se tem desenvolvido fundamentalmente sob motivações práticas. A sua parte elementar (Arranjos Simples, Permutações e Combinações, Polinômio de Newton) além de fazer parte do programa de ensino secundário, tem certas aplicações interessantes em áreas como a Geometria, Números, Jogos e Probabilidades. Além disso, “...é importante que os futuros professores sejam capazes de diferenciar leis que o cálculo combinatório define para fazer contagem e saibam analisar, no contexto da Resolução de Problemas, a utilização do raciocínio aditivo ou multiplicativo" (ALBUQUERQUE et al, 2010, p. 46).

A Análise Combinatória trata basicamente de problemas de contagem. As chamadas técnicas de contagem indireta surgiram em decorrência do trabalho de se contar diretamente os possíveis resultados de uma experiência. Isso pode se tornar muito penoso se as quantidades envolvidas forem muito numerosas. Daí a necessidade de se encontrar métodos gerais que permitam calcular o número de possibilidades de uma experiência, sem contá-las uma a uma (MENEGHETI, 2012, p. 68).

É conveniente destacar, tendo em vista a proposta da presente pesquisa, que os documentos curriculares estudados mostram uma significativa inclinação ao ensino dos assuntos da Análise Combinatória incorporados à Resolução de Problemas (RP). As recomendações curriculares brasileiras, influenciados por esta categorização, trazem em suas recomendações que o ensino de Análise Combinatória, dentro da Análise de Dados e Probabilidade, deve ser associado à Resolução de Problemas. Orientações Educacionais Complementares aos Parâmetros Curriculares Nacionais (PCNEM - BRASIL, 2002) ao discutir as estratégias para a ação na abordagem da Análise de Dados e Probabilidade traz que:

Para alcançar os objetivos estabelecidos de promover as competências gerais e o conhecimento de Matemática, a proposta do PCNEM privilegia o tratamento de situações-problema, preferencialmente tomadas em contexto real. A resolução de problemas é a perspectiva metodológica escolhida nesta proposta e deve ser entendida como a postura de investigação frente a 
qualquer situação ou fato que possa ser questionado (BRASIL, 2002, p. 129, grifo do autor).

Sob esta perspectiva, fica evidente que a Resolução de Problemas é uma ferramenta importante no processo de ensino-aprendizagem, ao contemplar os benefícios trazidos por muitas outras metodologias que eram foco de estudos anteriormente. Ela permite aprender de uma forma ativa, ajudar os alunos a construírem conhecimento matemático novo e também testar seus conhecimentos sobre os diversos temas de ensino.

A relação entre as competências visadas pelos PCNEM (BRASIL, 1999, 2002) e o desenvolvimento de habilidades relacionadas à Resolução de Problemas fica ainda mais evidente quando a Resolução de Problemas é mencionada de forma central

[...] o que se espera é que o aluno seja competente em resolução de problemas, se não de todos, pelo menos daqueles que permitam desenvolver formas de pensar em Matemática. A Resolução de Problemas é a peça central para o ensino de Matemática, pois o pensar e o fazer se mobilizam e se desenvolvem quando o indivíduo está engajado ativamente no enfrentamento de desafios (BRASIL, 2002, p.111).

A ênfase dada ao desenvolvimento de competências relacionadas à resolução de problemas se adequa às determinações dos Parâmetros Curriculares Nacionais (PCNs), de forma que a aquisição de conhecimentos específicos da área de Matemática se mistura ao desenvolvimento destas habilidades em um ambiente acadêmico que contemple a Resolução de Problemas.

\begin{abstract}
Assim, as funções da Matemática descritas anteriormente e a presença da tecnologia nos permitem afirmar que aprender Matemática no Ensino Médio deve ser mais do que memorizar resultados dessa ciência e que a aquisição do conhecimento matemático deve estar vinculada ao domínio de um saber fazer Matemática e de um saber pensar matemático. Esse domínio passa por um processo lento, trabalhoso, cujo começo deve ser uma prolongada atividade sobre resolução de problemas de diversos tipos, com o objetivo de elaborar conjecturas, de estimular a busca de regularidades, a generalização de padrões, a capacidade de argumentação, elementos fundamentais para o processo de formalização do conhecimento matemático e para o desenvolvimento de habilidades essenciais à leitura e interpretação da realidade e de outras áreas do conhecimento. (BRASIL, 1999, p.41)
\end{abstract}

É importante destacar que, como afirmam Cai \& Lester (2010), não existem evidências que reforçam a ideia de que, ao tratar do desenvolvimento de habilidades de resolução de problemas o professor sacrifica o espaço designado ao desenvolvimento de outras competências contempladas pelo ensino da Matemática. As habilidades básicas desenvolvidas no contexto da disciplina se desenvolvem em paralelo às de resolução de problemas quando se proporciona um ambiente de RP bem estruturado. 
Um esquema de aula no qual a abordagem seria através da Resolução de Problemas é proposto por Onuchic (2013), cuja esquematização consiste na formação de grupos, de forma que o professor assuma uma nova postura de mediador, na exposição, discussão e análise dos resultados obtidos pelos alunos, objetivando concordância entre os alunos, a formalização do conteúdo e, por fim, a proposição de novos problemas, conforme fig. 1

Figura 1: Ensino-aprendizagem-avaliação de matemática através da Resolução de Problemas

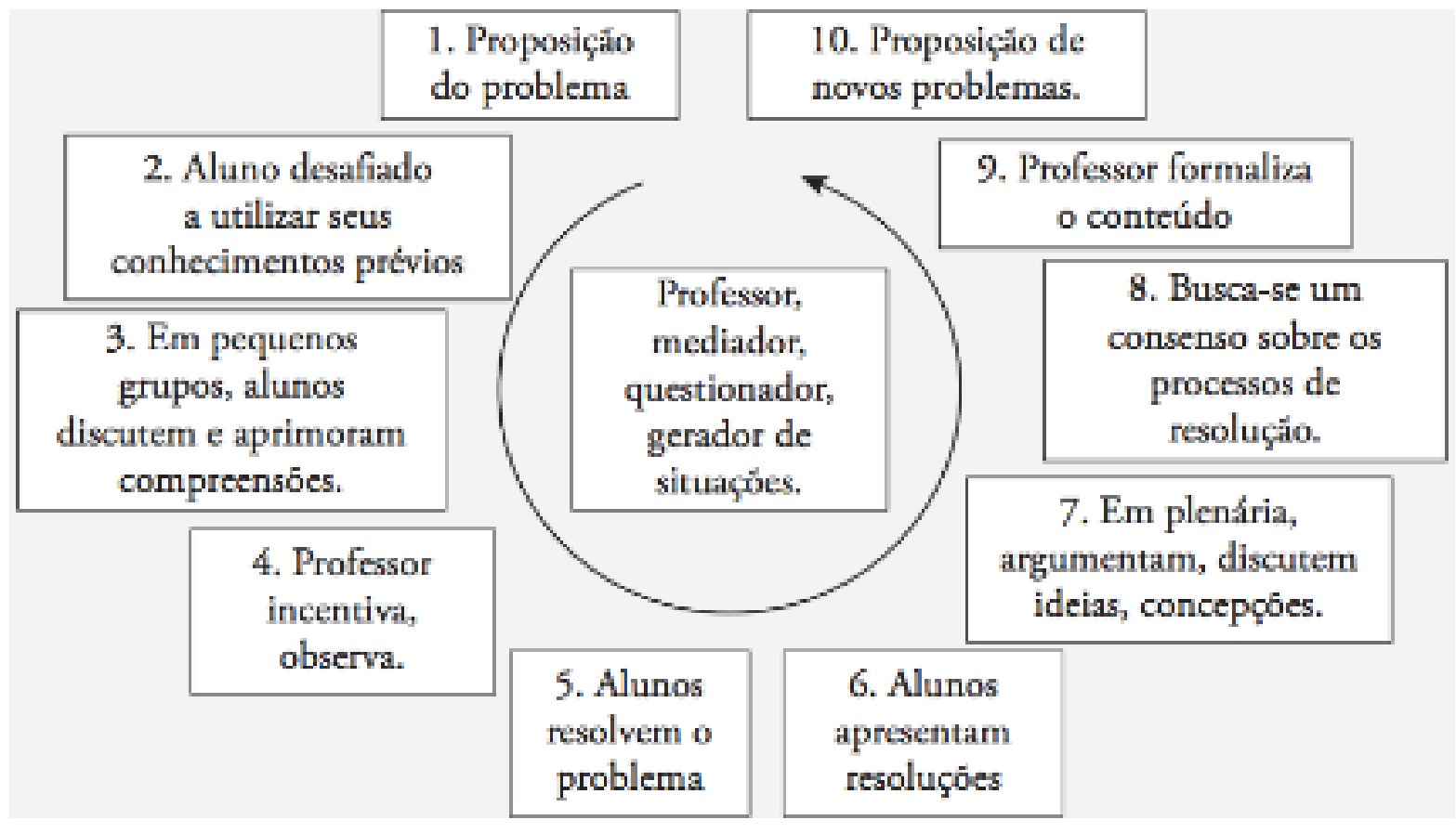

Fonte: Allevato e Vieira (2016)

O detalhamento do que significa e das ações que constituem cada uma dessas etapas pode ser encontrado em Onuchic et al (2014).

\section{Formulação de Problemas como Potencializador da Resolução de Problemas}

O que se vê costumeiramente é o professor solicitando ao aluno responder problemas, sejam estes apresentados pelo professor ou aqueles que constam no livro texto. Raramente, se é que isso algumas vezes acontece, é dada ao aluno a oportunidade de colocar ele próprio os seus problemas, não levando em consideração a importância da formulação de problemas pelos alunos, no seu processo de aprendizagem.

A formulação de problemas é uma atividade que pode ser incorporada à Resolução de Problemas de modo a colocar o aluno em uma perspectiva de construção, para que se desenvolva de forma independente e crítica. Silver (1996, p. 141) afirma que “...a formulação de problemas refere-se quer à criação de novos problemas, quer à reformulação de problemas já existentes" e pode ocorrer antes, durante ou depois da solução de um problema. 
Há algumas estratégias que poderão ser úteis para facilitar o processo de formulação de problemas. Boavida, Paiva, Cebola e Pimentel (2008) citam duas delas: "E se em vez de?" e "Aceitando os dados". Trabalha-se com a abordagem intitulada "e se em vez de?" ao propor a formulação de problemas a partir de informações contidas em um problema já existente e da modificação ou restrição de aspectos do mesmo, em suma, trata da modificação de problemas. Na abordagem designada por "aceitar dados", propõe-se a formulação de problemas a partir de um conjunto de dados (expressões, tabelas, imagens, etc.) e da definição de objetivos que sejam incorporados pelo problema, trata-se especificamente da criação de problemas. Esta abordagem é rica e interessante, no entanto, Boavida et al (2008) alertam que ela deve ser realizada depois que o aluno tem uma certa familiaridade em etapas anteriores, como a modificação de problemas, pois "uma atividade de invenção sem um suporte prévio pode levar os alunos a fantasiar, simplesmente criando problemas sem nenhuma ligação à Matemática ou então propondo problemas tão complicados que nem os conseguem resolver" (BOAVIDA et al, 2008, p. 29).

Tanto os aspectos vistos por muitos de forma dissociada da Matemática (criatividade e atratividade, por exemplo) quanto os aspectos naturalmente contemplados pela disciplina (busca por otimização, compreensão ou apropriação conceitual) podem ser incorporados às atividades de formulação de problemas. Silver (1996) apresenta três conclusões a que chega a partir das investigações em torno da formulação de problemas:

Primeiro, é claro que as tarefas de formulação de problemas podem fornecer aos investigadores, tanto uma janela através da qual observa o pensamento matemático dos alunos, como um espelho onde são refletidas as suas experiências matemáticas. Segundo, as experiências de formulação de problemas fornecem um campo potencialmente rico no qual se pode explorar a interligação entre as dimensões cognitiva e afetiva da aprendizagem da Matemática pelos alunos. Por último, é necessária uma investigação muito mais sistemática sobre o impacto das experiências de formulação de problemas nas capacidades dos alunos formularem problemas, resolverem problemas, compreenderem ideias matemáticas e na sua disposição em relação à Matemática (SILVER, 1996, p. 155).

Destaca-se, também na fala dos autores (BOAVIDA et al, 2008; KILPATRICK, 1987; SILVER, 1996), a importância da formulação de problemas como uma atividade em si, e não somente como um meio de instrução. Segundo VANLEHN (1984 apud KILPATRICK, 1987), à medida que aumenta o acesso a ferramentas tecnológicas de execução algorítmica, aumenta a importância conferida à problematização de situações, o que incide diretamente na importância da habilidade de formular de problemas.

Tanto professores quanto estudantes assumem que problemas simplesmente existem, como montanhas a ser escaladas, e eles raramente questionam como podem ser dadas formulações alternativas aos problemas, muito menos de onde eles vêm originalmente (KILPATRICK, 1987, p. 123, tradução nossa). 
Desta forma, deve-se desaprovar da noção concretizada de que problemas "simplesmente existem" e direcionar a atenção ao desenvolvimento do caráter de formulador de problemas nos estudantes em paralelo ao de solucionador de problemas.

A par da resolução de problemas, a formulação de problemas é uma atividade de importância inquestionável, pois contribui não só para o aprofundamento dos conceitos matemáticos envolvidos, mas também para a compreensão dos processos suscitados pela sua resolução. Encorajar os alunos a escrever, a partilhar e a resolver os seus próprios problemas, é um contexto de aprendizagem muito rico para o desenvolvimento da sua capacidade de resolução de problemas. Ao colocarem problemas, os alunos apercebem-se da sua estrutura, desenvolvendo, assim, pensamento crítico e capacidades de raciocínio ao mesmo tempo que aprendem a exprimir as suas ideias de modo mais preciso (BOAVIDA et al, 2008, p. 27).

É importante destacar que, na formulação de problemas, o aluno é desafiado a problematizar situações do dia a dia usando a sua própria linguagem, vivências e conhecimentos e, nesse sentido, diz Boavida et al (2008), que o professor deve dar especial atenção a alguns aspectos: um é usar as formulações apresentadas pelos alunos no sentido de os orientar para exploração matematicamente rica. Outro é saber aproveitar as situações que ocorrem na sala de aula, quer sejam provocadas ou ocasionais, para proporcionar atividades de formulação de problemas: um aniversário, uma visita de estudo ou a celebração de um Dia Mundial.

Assim, dada a conexão nítida entre estas duas vertentes, a Resolução de Problemas e a Formulação de Problemas, a pesquisa busca trabalhar com ambas no mesmo contexto, baseando-se no aporte teórico que mostra que esta proposta de atividade é alcançável e que a utilização de ambas abordagens mostra resultados satisfatórios.

\section{Percurso Metodológico}

Com o objetivo central de verificar os benefícios trazidos pela utilização da Metodologia de Ensino-aprendizagem-avaliação de Matemática através da Resolução de Problemas no desenvolvimento do raciocínio combinatório, propôs-se a criação de um minicurso, com três encontros de $5 \mathrm{~h}$, em uma universidade pública da Bahia, a 15 (quinze) estudantes do $10^{\mathrm{o}}$ semestre de um curso de Licenciatura em Matemática. O minicurso contemplou os seguintes conteúdos: Princípio Fundamental de Contagem; Arranjo; Permutação e Combinação. A par destes conteúdos foram tratadas noções relacionadas à compreensão de conceitos em torno dos processos de contagem indireta e a determinação de fórmulas que generalizem a resolução dos problemas propostos, ou seja, a criação de algoritmos contemplados pela Análise Combinatória. 
O planejamento dos encontros foi feito segundo os modelos estabelecidos por Onuchic et al., 2014 ${ }^{18}$, o ambiente da sala de aula foi caracterizado pela metodologia de Resolução de Problemas proposta por Onuchic (2013) e, na preparação dos problemas, utilizamos produções didáticas como as de Rosen (2011) e Krantz (2009). Os problemas foram retirados da publicação "Discrete Mathematics and Its Aplications" de Kenneth H. Rosen e modificados para que se adequassem à proposta de aula através da RP.

As tarefas (problemas) foram propostas pelo segundo autor deste artigo que assumiu o papel de professor-pesquisador. "A formulação de boas questões de investigação, o estabelecimento de um plano de trabalho e as técnicas utilizadas para recolha de dados permitem que a estreita relação entre professor-pesquisador e sujeitos da pesquisa seja superada, conferindo validade à pesquisa” (ALLEVATO \& VIEIRA, 2016, p.122-123).

A recolha de dados foi feita pelas produções escritas dos alunos, pelas observações dos diálogos produzidos pelos alunos no momento da realização do problema, das discussões no grupo, da plenária e os registros na lousa.

E, para analisar as produções dos alunos realizadas mediante a utilização da Metodologia de Ensino-aprendizagem-avaliação de Matemática através da Resolução de Problemas optou-se por uma análise de natureza qualitativa, devido ao seu caráter subjetivo e exploratório, que visa compreender mais o processo do que o produto das situações de ensino e aprendizagem.

${ }^{18}$ O problema, a série recomendada, objetivo(s), conteúdos abordados, estratégias, formulação e extensão do problema. 
Quadro 1: Problemas apresentados nos encontros durante o minicurso

Problema 1: Dados os conjuntos $A, B$ não vazios. Uma função $f$ é uma aplicação de $A$ para $B$ onde para cada elemento pertencente a $A$ existe um, e apenas um elemento associado em $B$. Em uma função injetora, $f(a)=f(b) \Rightarrow a=b$.

a) Quantas funções injetoras temos de um conjunto domínio de 2 elementos para um contradomínio de com 4 elementos?

b) Utilizando dois conjuntos genéricos seguindo as especificações da questão anterior, liste as possíveis funções encontradas.

c) Levando em conta agora, um conjunto A com m elementos e um conjunto B com $\mathrm{n}$ elementos, existe alguma limitação para a existência de funções injetoras $f: A \rightarrow B$ ? Quantas funções $f$ distintas existem?

Problema 2: Um professor, disposto a realizar um projeto na escola em que leciona, deve escolher aquele a ser aplicado dentre os projetos de 3 diferentes listas com 22, 11 e 15 projetos distintos.

a) Quantos possíveis projetos podem ser escolhidos?

b) Quantas possibilidades de projetos haveria se existissem $n$ listas com $a_{1}, a_{2}, a_{3}, \cdots, a_{n}$ projetos distintos?

Problema 3

a) De quantas formas diferentes podemos arranjar o conjunto de letras $A B C D E F G H$ ?

b) Em um segundo momento, a sequência $A B C$ deve ser mantida. De quantas formas o conjunto pode ser arranjado?

\section{Problema 4:}

Cem bilhetes, numerados de 1 a 100, são vendidos para um sorteio a 100 pessoas diferentes. O sorteio premiará 4 pessoas diferentes. De quantas formas podem ser premiados os participantes do sorteio se:
a. Houver 4 prêmios diferentes?
b. Houver 4 prêmios diferentes e o número 47 ganhar um dos prêmios?
c. Houver 4 prêmios diferentes e o número 47 não for premiado?
d. Houver 4 prêmios diferentes e os números 19, 47, e 73 forem premiados?
e. Os prêmios forem idênticos?

Analisando as resoluções anteriores, encontre uma fórmula que generalize arranjos de $r$ elementos em conjuntos $\operatorname{com} n$ elementos.

Dado um conjunto com $n$ elementos, quantas combinações de $r$ elementos pertencentes a este conjunto podem ser feitas, de forma que não haja repetições?

\section{Construção das autoras}




\section{Analisando e interpretando os dados}

Como dito anteriormente, o minicurso foi realizado em três encontros e, no âmbito deste artigo, a análise e interpretação dos dados recolhidos será com base em alguns dos problemas realizados durante os encontros, seguindo as orientações metodológicas propostas por Onuchic (2013) ao trabalhar com a RP (leitura do problema, formação dos grupos, resolução dos problemas, discussão nos grupos, intervenção e mediação do professor, plenária, busca de um consenso, formalização e proposição de novos problemas).

Em breves palavras, no primeiro encontro, expôs-se um pouco acerca da pesquisa que estava sendo realizada, falando brevemente sobre a RP e a Análise Combinatória, aproveitando da natureza de formação de professores onde o curso foi aplicado.

Antes da entrega dos problemas, os alunos foram separados em três grupos. De posse do problema 1, leram primeiramente de forma individual, e depois discutiram o mesmo em grupo. Sem assinalarem problemas quanto à compreensão do enunciado dos problemas, os participantes do curso prosseguiram, iniciando a sua resolução dentro de seus respectivos grupos.

No item 1 do problema 1, o objeto de discussão inicial dentre os grupos era a forma com a qual o fato da função ser injetora afetaria a resolução. Um aluno do grupo 1 defendeu que seriam duas funções, porém, não deu uma justificativa clara nem aos pesquisadores nem aos seus colegas de grupo. Sua ideia foi, portanto, abandonada e os componentes do grupo seguiram em busca de outras estratégias de resolução. Onuchic \& Allevato (2011, p. 84) afirmam que "A partir do entendimento do problema, sem dúvidas quanto ao enunciado, os alunos, em seus grupos, em um trabalho cooperativo e colaborativo, buscam resolvê-lo". Este trabalho cooperativo exige dos alunos a capacidade de se comunicar matematicamente. Não havendo esta comunicação, não há progresso na chegada ao consenso grupal.

No Grupo 2, os alunos, tratando um conjunto $A=\{a, b\}$, perceberam que, devido à injetividade requerida pelo enunciado, existiam quatro possibilidades para $f(a)$ e havendo associado " $a$ ", restariam três elementos possíveis para associar a $f(b)$, porém, não conseguiam perceber, naquele momento, de que forma esses números se associavam.

O Grupo 3 concluiu o mesmo ao ilustrar também um conjunto genérico. Os alunos dos três grupos conseguiram alcançar a solução, alguns utilizaram a resolução do item 2 do problema 1 para que pudessem resolver a primeira atividade através do processo de contagem direta. Por mais que a "mudança" da ordem de alteração tenha ocorrido, a validade da resolução não é questionável, já que eles utilizaram de uma estratégia que tinham ao seu alcance, não se apoiando em procedimentos previamente aprendidos, e, como nosso aporte teórico defende: À medida que os estudantes resolvem problemas, eles podem usar qualquer abordagem imaginável, extrair qualquer pedaço de conhecimento que aprenderam, e 
justificar suas ideias de maneiras que eles sintam ser convincentes (CAI \& LESTER, 2010, p. 3, tradução nossa).

Ao chegarem no item 3 do $1^{0}$ problema, os participantes logo encontraram obstáculos. A generalização solicitada pelo item 3 se mostrou complexa, e foi necessária a intervenção dos pesquisadores com questionamentos do tipo: O que ocorre quando você muda o número de elementos do domínio? E do contradomínio? Estes questionamentos levaram os alunos a testar valores e buscar padrões. Neste momento, a postura adotada pelo professor no contexto da RP se destaca. Estes questionamentos levaram os alunos a testar valores e buscar padrões, a fim de solucionar problemas secundários, conforme Nunes (2015) esclarece

[...] é necessário que o professor atenda os alunos em suas dificuldades, colocando-se como interventor e questionador. Acompanha suas explorações e ajuda-os, quando necessário, a resolver problemas secundários que podem surgir no decurso da resolução do problema: passagem da linguagem vernácula para a linguagem matemática, e, conceitos relacionados e técnicas operatórias, a fim de possibilitar a continuação do trabalho (NUNES, 2015, p. 74-75, grifo do autor).

Além disso, como apresentado por Cai \& Lester (2010), é necessário que o professor se atente a não retirar do problema sua natureza problemática, é preciso que os alunos se esforcem mentalmente para que alcancem a resolução. A realização de questionamentos, ao invés do apontamento de soluções, instiga este processo e mantém o caráter problemático da tarefa, encarregando aos alunos a sua resolução.

Os grupos 1 e 3 adotaram a estratégia de, primeiramente, fixar um valor para o número de elementos do domínio e variar o número de elementos do contradomínio, e em seguida, fixar um valor para o número de elementos do contradomínio e variar o número de elementos do domínio. A partir desta estratégia, o Grupo 1 conseguiu perceber o processo multiplicação envolvido, porém, ainda teve problemas em escrevê-lo em termos de $m$ e $n$, como vemos na figura abaixo.

Figura 2 - Registro do Grupo 1: busca por um padrão

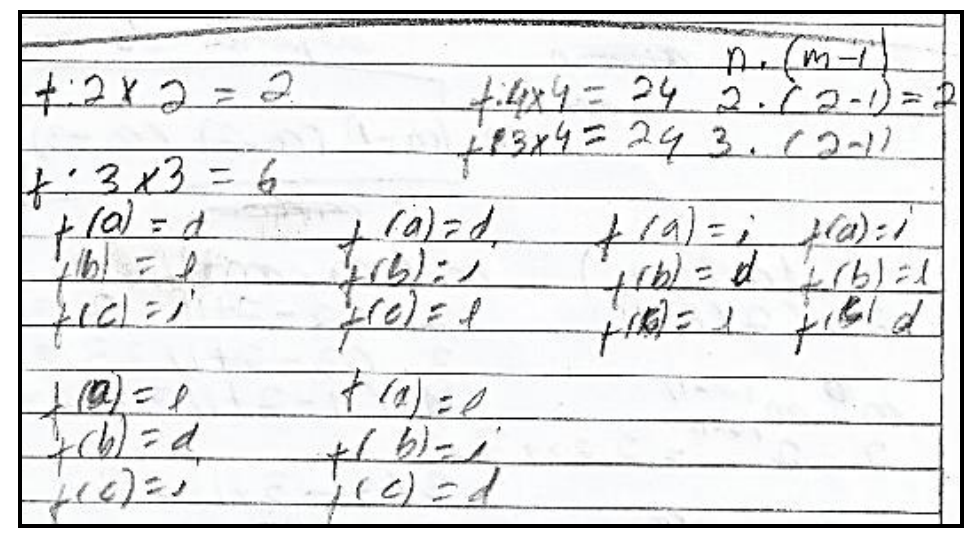

Registro das atividades, documentos das autoras 
Apesar de dois dos grupos não alcançarem a solução do item 3, era perceptível que eles enxergavam um padrão, mas não conseguiam escrevê-lo em termos de $m$ e $n$. O grupo que mais se aproximou da generalização foi o grupo 1, cuja estratégia pode ser vista na figura 3 .

Figura 3 - Registro do Grupos 1: busca pela generalização

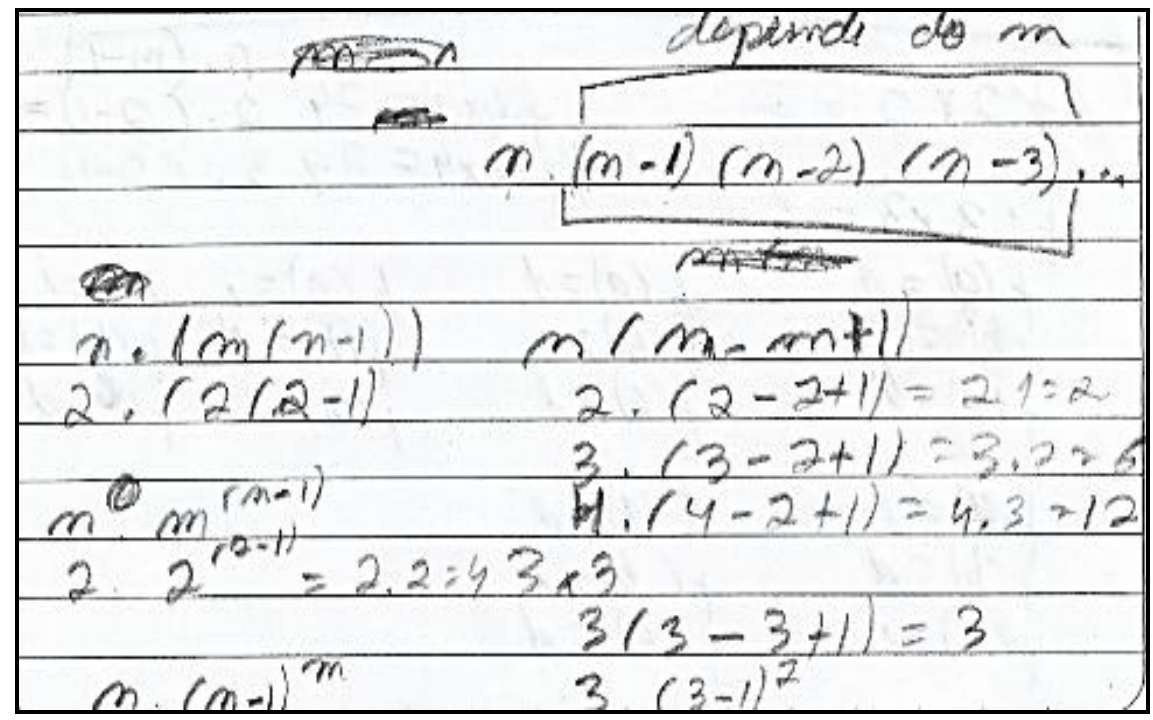

Registro das atividades, documentos das autoras

Mesmo o problema não tendo como objetivo central a busca por padrões, é pertinente ressaltarmos aqui, que o ensino de Matemática deveria ser direcionado para o desenvolvimento de capacidades de generalizar e fundamentar generalizações, pois o reconhecimento de padrões, segundo Vale e Pimentel (2011), permite que a aprendizagem da Álgebra se processe de um modo gradual e ajuda a desenvolver a capacidade de abstração, essencial no desenvolvimento de capacidades matemáticas.

Convidamos os grupos à lousa para que expusessem suas respectivas soluções. Quanto aos itens 1 e 2, não houve problema para que se alcançasse o consenso, apesar dos grupos representarem os conjuntos mencionados nas questões de diferentes formas. Utilizaram raciocínios similares, apenas algumas correções quanto à representação simbólica das soluções foram necessárias.

O momento de formalização ocorreu de forma fluente, visto que todos os alunos haviam compreendido as soluções expostas no momento de socialização. O termo "Regra do Produto" lhes foi apresentado como o Princípio Fundamental da Contagem e a técnica que eles haviam utilizado foi formalizada.

Havendo finalizado o Problema 1, deu-se início à resolução do segundo problema, seguindo os mesmos parâmetros anteriores, inicialmente, propondo a leitura dos problemas para que o enunciado fosse compreendido. Seguindo com a resolução, os grupos 
solucionaram o problema com bastante rapidez, de forma que, mesmo após encontrarem a solução, partiram em busca de variáveis e características implícitas ao problema, pois, segundo eles: "tem alguma coisa errada, foi fácil demais!". Estavam equivocados, realmente haviam chegado à conclusão correta, porém, este momento de discussão e busca se mostrou muito rico.

A solução do item 2 seguiu com a mesma fluência, logo, todos os grupos haviam chegado à conclusão. No momento da exposição os alunos discutiram acerca de detalhes que haviam observado quando supunham modificações ao enunciado, por exemplo, "e se o professor quisesse escolher 2 projetos dentre estas listas? E se ele quisesse escolher um de cada lista? ", o que evidenciava a forma com a qual a resolução do problema anterior, acerca da Regra do Produto, havia ocorrido de forma expressiva, de modo que eles buscavam formas coerentes de incorporá-la à novas situações propostas.

A formalização deste novo conceito ocorreu sem maiores eventos, o mesmo lhes foi apresentado como "Regra da Soma”, e foi realizada uma "extensão" da discussão que haviam iniciado anteriormente, no qual se pôde comparar os parâmetros que demandaram o uso da Regra da Soma ao invés da Regra do Produto.

Para o segundo encontro foram propostos dois problemas (problemas 3 e 4 , ver Quadro 1) que teve como objetivo, para o professor, inserir os conceitos de Arranjo e Combinação, com ênfase situacional na diferença entre os mesmos e objetivos para o aluno: distinguir, em diferentes situações, de que forma prosseguir com o processo de contagem e aplicar diferentes métodos de contagem, dadas as especificidades de cada situação.

Este encontro iniciou-se com a apresentação do problema. Como os participantes já haviam se familiarizado com a proposta da aula do encontro passado então, de início, foi pedido a eles que se organizassem nos mesmos grupos da aula anterior e, a seguir, foram entregues as novas atividades, pedindo para que lessem o Problema 3.

Sem muita discussão, os grupos enxergaram a aplicabilidade da Regra do Produto, chegando rapidamente à solução do item 1. Quanto ao item 2, o grupo 3 questionou se o enunciado demandava a manutenção da posição da sequência "ABC", novamente, os pesquisadores voltaram a atenção dos alunos deste grupo ao enunciado, destacando que a solução do problema deve satisfazer o enunciado e que adicionar variáveis ao mesmo poderia levar à uma solução equivocada. Após as orientações, os alunos seguiram com a resolução, e logo, todos os grupos haviam encontrado a solução.

O momento de exposição das soluções e busca por consenso ocorreu sem problemas, todos os grupos alcançaram a solução. O grupo 3 mencionou a sua preocupação quanto ao posicionamento da sequência "ABC", mas os outros grupos responderem de forma similar às orientações dos pesquisadores, um dos alunos afirmou que “...se a questão não pediu não tem 
por que você se preocupar com isso, se a questão quisesse que fosse a mesma posição ela ia pedir a mesma posição.”

Finalizando esta seção do encontro, a definição de Permutação Simples e sua representação foi apresentada e formalizada aos alunos sem que levantassem dúvidas.

A leitura do problema 4(Quadro 1) exigiu mais tempo, devido à extensão e complexidade da diferenciação entre as questões, em especial do item 1. Ao dar início à resolução dos problemas, os grupos, internamente, discutiam acerca da implicação do fato de os prêmios serem diferentes ou iguais. Este contexto evidencia a discrepância referida pelos PCN (BRASIL, 1997, 1998, 1999, 2002) no ensino de Análise Combinatória puramente através de fórmulas. Dadas as variações entre os enunciados das questões, a aplicação das fórmulas perde, quase que por completo, sua ênfase. O desafio na resolução do problema 2 trata mais da compreensão das implicações das características apresentadas nos enunciados. A figura abaixo ilustra a forma com a qual os alunos do grupo 3 tentavam incorporar a regra da soma às variações do enunciado do item 1 :

Figura 4 - Resolução do Grupo 3: Problema 2

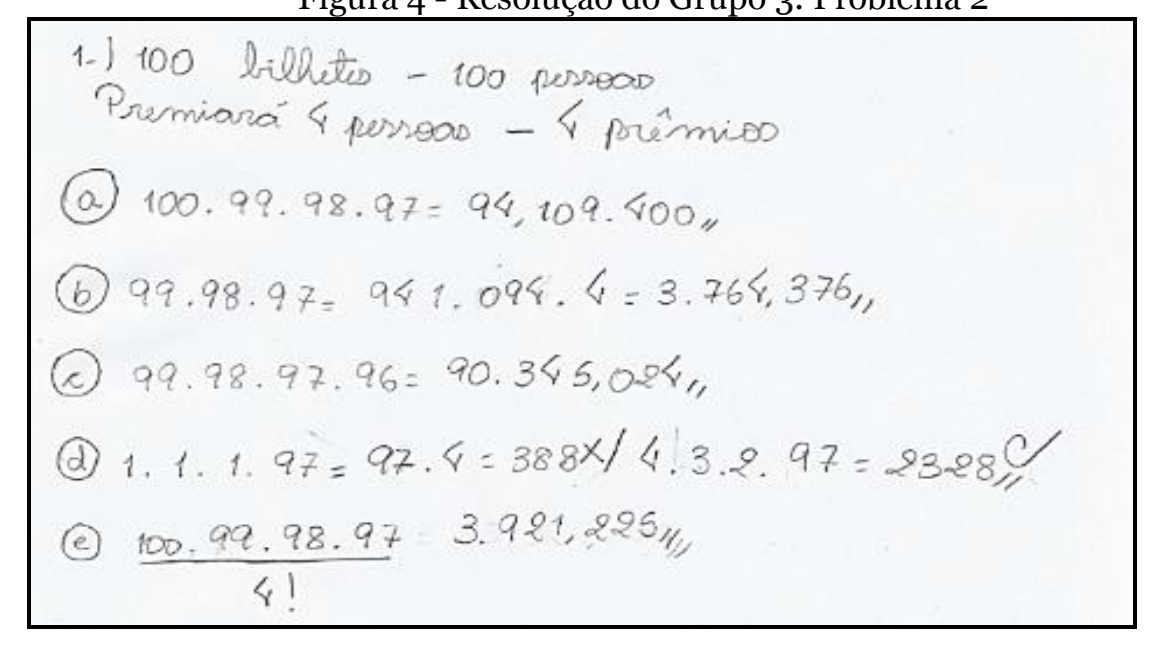

Registro das atividades, documentos das autoras

No grupo 2, como estratégia ilustrativa, os membros decidiram escolher, de forma arbitrária, prêmios para que esclarecessem as implicações de os mesmos serem diferentes ou iguais. Logo perceberam que, com prêmios diferentes, além das possibilidades de vencedores, ainda teriam que levar em consideração as possibilidades de prêmios, enquanto com prêmios iguais teriam de levantar apenas as possibilidades de vencedores, já que qualquer um dos prêmios que estes recebessem não geraria uma nova "premiação".

Um dos membros do grupo 1, concluiu que como teriam que levar em conta, além dos possíveis vencedores, os possíveis prêmios que cada um destes ganharia, eles usariam a Regra do Produto e multiplicariam o resultado por 4 (quatro), devido à quantidade de 
prêmios, seus colegas discordaram, afirmando que acreditavam que a regra do produto já incorporava em si a diferenciação dos prêmios, e que, quando os prêmios fossem idênticos, eles haveriam de fazer algo para reduzir as possibilidades que contemplam os mesmos vencedores, porém, premiados em ordens diferentes, já que, independentemente da ordem, os prêmios seriam iguais.

Os grupos seguiram tentando incorporar estratégias às demandas que cada questão fazia, e discutindo de que forma as fazer, porém, os membros do grupo 1 ainda não haviam chegado a um consenso interno quanto à diferenciação dos prêmios, mesmo após a intervenção dos pesquisadores. A discussão se estendeu ao restante da turma, quando uma aluna do grupo 3 interferiu buscando explicar de que forma a regra do produto contemplava o fato dos prêmios serem distintos.

O momento de discussão que seguiu foi muito rico e, como Allevato \& Onuchic (2014) afirmam, “...esse é um momento em que ocorre grande aperfeiçoamento da leitura e da escrita matemáticas e relevante construção de conhecimento acerca do conteúdo”. Mesmo que tenha antecipado à plenária segundo o roteiro, como pesquisadores, tomamos a decisão de mediar esta discussão ao invés de interrompê-la, já que sua natureza argumentativa era uma plataforma de aprendizagem apropriada para a aula, e seu desenvolvimento não ocorreu de forma contraproducente.

Finalizando a discussão, os alunos retornaram à resolução dos problemas, restando então os itens 4 e 5, que correspondiam à generalização dos conceitos vistos. Os grupos 2 e 3 encontraram dificuldades no processo de generalização, já o grupo 1, logo se apropriou da generalização feita no $1^{\mathrm{o}}$ encontro e buscou incorporar a ela a Permutação Simples, desta forma, encontraram também a solução do item 5. Eventualmente, o grupo 3 também chegou a uma conclusão, e, apesar de o grupo 2 não alcançar a generalização, precisamos seguir para o momento da exposição das soluções.

Ao expor suas soluções, os grupos mostraram mais divergências, o que levava a discussões a respeito do que a questão demandava que se incorporasse ao cálculo. Em muitas ocasiões, os grupos percebiam que haviam levado em consideração uma das demandas da questão que outro grupo não havia considerado e que a solução correta seria encontrada ao se combinar os raciocínios dos grupos, a cooperação enriqueceu muito o momento de busca por consenso. Ao final deste momento, devido ao fato de 2 dos grupos encontrarem a generalização, a formalização ocorreu de forma fluida, destacando-se com mais ênfase a aplicabilidade situacional das fórmulas.

O segundo encontro foi finalizado com uma proposta de formulação de problemas que incorporassem os conceitos vistos nos dois encontros para que fossem discutidos no encontro seguinte. Neste momento, os alunos foram orientados individualmente, pelos 
pesquisadores a buscar situações que contemplassem os conceitos vistos, sem se preocupar com a complexidade, e que, após definir um objetivo dentro do contexto conceitual explorado, compusessem o problema buscando extrair de sua resolução o máximo de conceitos possível, conforme a estratégia sugerida por Boavida et al (2008) e mencionada anteriormente - Aceitando os dados.

No terceiro encontro, buscou-se incorporar um novo elemento da Resolução de Problemas que desviou um pouco do modelo sugerido por Onuchic (2014), a Formulação de Problemas como base teórica central Edward A. Silver (1996), objetivando uma concretização dos conceitos e raciocínios vistos nos encontros anteriores. Cabia ao professor, durante a finalização da composição dos problemas pelos alunos, seguir uma postura similar à postura adotada durante a resolução dos problemas propostos nos encontros passados, observando e incentivando os alunos ao mediar suas construções. Em seguida, os problemas foram expostos, discutidos e solucionados por seus respectivos compositores individualmente na lousa.

A formulação dos problemas foi diversificada, alguns alunos deram ênfase à aplicabilidade lógica do conteúdo, como:

Figura 5 - Problema Confeccionado A

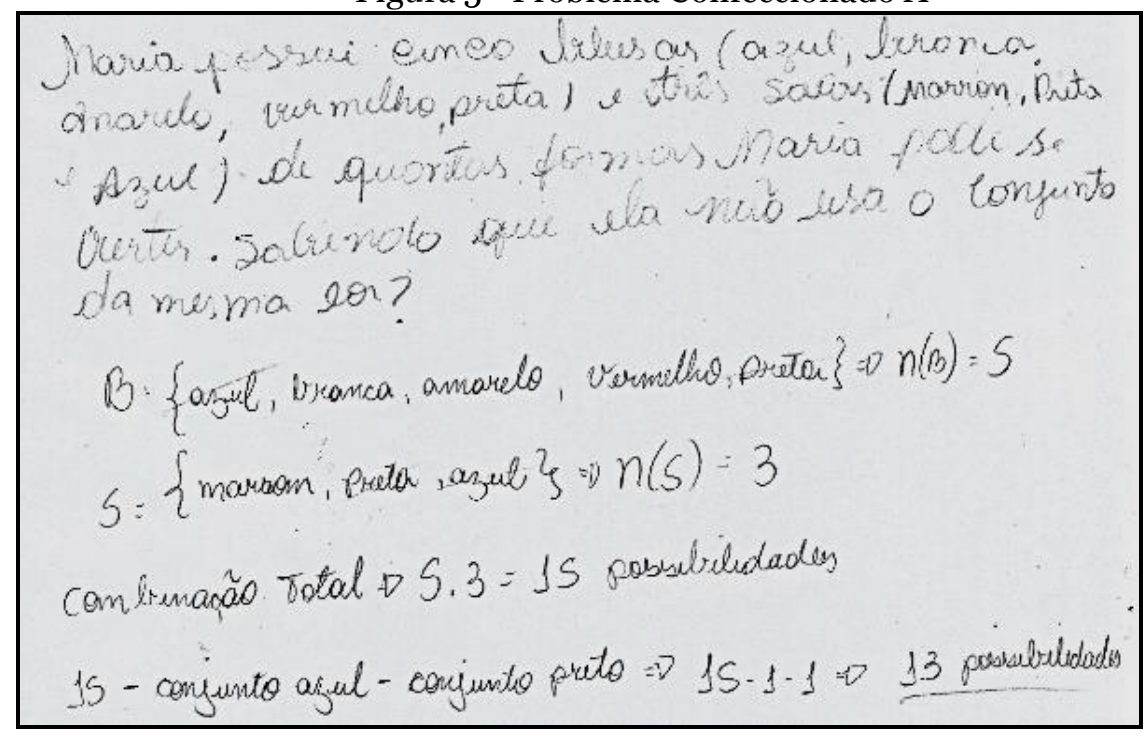

Registro das atividades, documentos das autoras

A questão, apresentada na Figura 5, produzida por um dos alunos busca incorporar a "exclusão" de possibilidades dentro de um conjunto amplo. Outras produções enfatizaram a aplicação do conteúdo de forma sistemática, o que reflete não só a forma com a qual o processo de ensino é visto por estes alunos, mas também, a dissociação feita por eles entre Matemática e criatividade. 
Um dos alunos, em especial, adotou uma abordagem interessante à nossa proposta ao confeccionar um problema que pudesse ser utilizado para que se introduzisse o Princípio Fundamental da Contagem através da resolução de problemas.

Figura 6 - Problema Confeccionado B

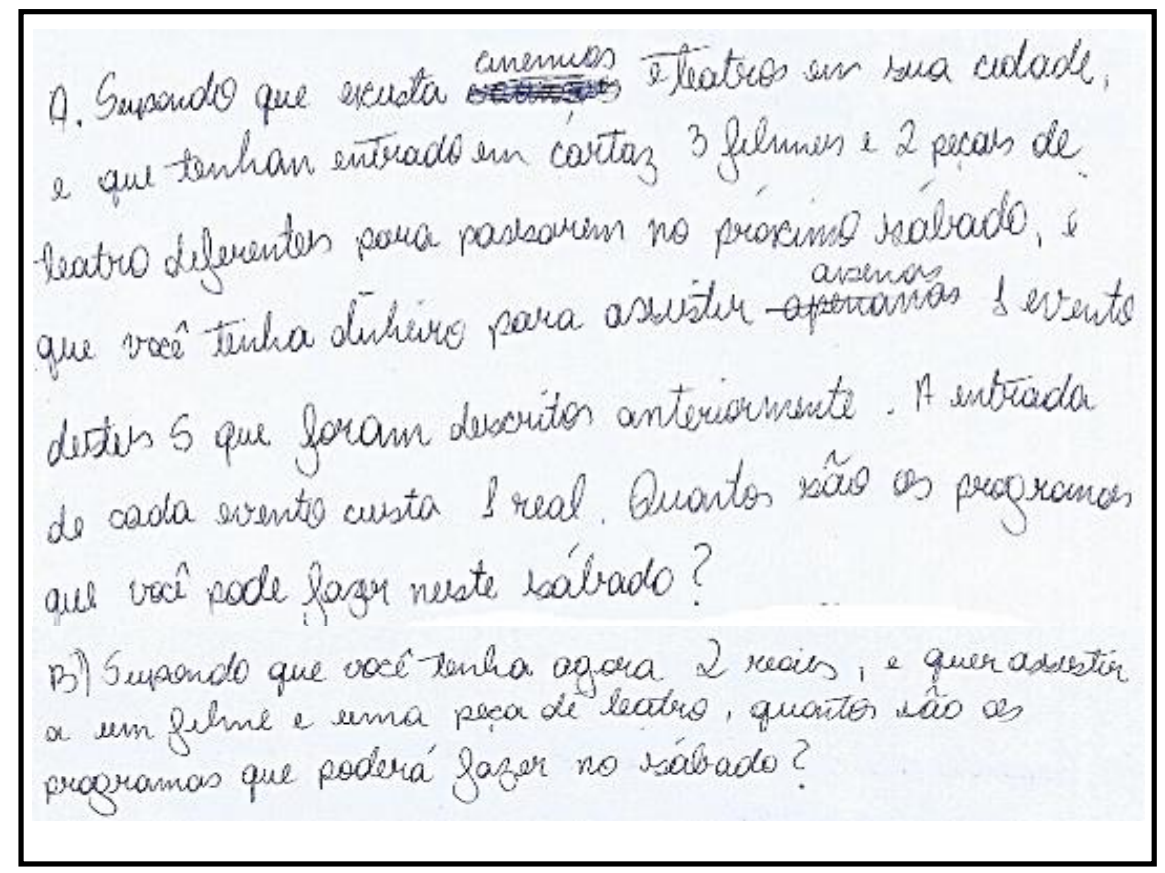

Registro das atividades, documentos das autoras

Esta postura de produção adotada evidencia de forma nítida a maneira com a qual a utilização da Resolução de Problemas no âmbito de formação docente influi solidamente na visão didática de futuros professores, dando acesso a práticas metodológicas que seriam experimentadas de duas perspectivas distintas, como aluno e como professor.

Ademais, a formalização (produção) do problema acima revelou o desenvolvimento do raciocínio combinatório, quando dada uma situação na qual há várias possibilidades de construção de agrupamentos, de caminhos, fornecendo um tipo específico de interpretação quando se devem considerar os resultados possíveis para cada um desses agrupamentos ou caminhos.

Destacou-se neste momento a permissividade gerada pela formulação de problemas para que pudesse ser analisada as perspectivas dos estudantes durante suas respectivas formulações. Afinal, retomando ao aporte teórico, Silver (1996, p. 155) defende que "[...] as tarefas de formulação de problemas podem fornecer aos investigadores, tanto uma janela através da qual observar o pensamento matemático dos alunos, como um espelho onde são refletidas as suas experiências matemáticas". 
A discussão centralizou-se em torno da aplicabilidade da metodologia, a criação de uma cultura de sala de aula que incorporasse em si a Resolução de Problemas de forma integral. Um dos participantes apontou a dificuldade de se criar este ambiente no ensino público devido ao contexto social, que muitas vezes vem carregado de problemáticas que fogem ao acesso do professor, e afetam diretamente o desempenho dos alunos.

Em seguida, apresentou-se aos participantes do minicurso, um texto sobre Matemática Discreta ${ }^{19}$ (criado pelo segundo autor deste artigo, adaptado de Rosen, 2007 e de NCTM, 2000) e, a partir dele, discutiu-se a respeito das especificidades do conteúdo visto, provocando questionamentos como: Numa visão geral, de que maneira a Análise Combinatória é contemplada? E como a aprendizagem da Matemática Discreta pode proporcionar um ambiente rico não só para a Resolução de Problemas, mas também, para o desenvolvimento de alunos críticos e argumentativos?

A discussão funcionou como um catalizador do processo, evidenciando os efeitos da aplicação do minicurso e trazendo uma análise geral do desenvolvimento do pensamento combinatório dos participantes no decorrer do curso e apresentando uma interface entre ser um aluno em um ambiente de RP e as perspectivas criadas para se tornar um professor utilizador da RP.

\section{Considerações Finais}

Retomando à pergunta de pesquisa, quais benefícios a Metodologia de EnsinoAprendizagem-Avaliação de Matemática através da Resolução de Problemas pode trazer aos futuros professores do curso de Licenciatura em Matemática em se tratando da Análise Combinatória? É apresentada a seguir uma série de atributos que foram evidenciados através da coleta e análise dos dados.

Inicialmente, a pesquisa evidenciou que um cenário de RP bem estruturado alimenta uma cultura de sala de aula onde se desenvolve uma Matemática crítica e argumentativa. Os episódios observados no curso destacaram a necessidade de que se justifique o pensar matemático, levantando a necessidade de que se aprenda matemática de forma substancial, e não sistémica como é comumente observado em salas de aula contemporâneas.

O aluno, na perspectiva da RP, é estimulado a assumir uma postura ativa, sob a qual o aprendizado ocorre de maneira particular, respeitando os aspectos singulares de cada indivíduo e os colocando em posição de responsabilidade ao demandar certo nível de

19 Texto disponível no Apêndice C do Trabalho de Conclusão de Curso de Thaylan Campeche Vidal - UNEB, 2016. 
autonomia no desenvolvimento das aulas. Este aspecto remete à cultura de sala mencionada anteriormente. Cultivar um ambiente de aprendizagem eficaz e saudável é de suma importância, e como defendemos, a Resolução de Problemas pode funcionar como uma plataforma neste processo.

Tratando especificamente da RP, a partir das observações feitas, destacam-se as habilidades às quais se estimula com mais ênfase ao trabalhar com a metodologia. Em um primeiro momento, a capacidade de interpretação de enunciados é diretamente acessada através da Resolução de Problemas. A forma com a qual a RP dá ênfase à leitura e à compreensão dos problemas propostos engloba de forma clara o desenvolvimento desta capacidade, de forma que o passo inicial do processo é centrado na determinação e delimitação da proposta trazida no enunciado dos problemas geradores. Destacamos que, quanto ao contexto de aplicação da RP, Onuchic \& Allevato (2011) afirmam que

[...] nesta metodologia, os problemas são propostos aos alunos antes de lhes ter sido apresentado, formalmente, o conteúdo matemático necessário ou mais apropriado à sua resolução que, de acordo com o programa da disciplina para a série atendida, é pretendido pelo professor (ONUCHIC \& ALLEVATO, 2011, p. 85).

Significando que, é esperado que os alunos não tenham em seu escopo de algoritmos algum que venha a solucionar o problema proposto, desta forma, devem desenvolver suas capacidades de dedução lógico-matemática, traçando conexões entre assuntos prévios e possíveis formas de desenvolver novos métodos de resolução que supram a problemática em mãos.

O termo "argumentação matemática" tem um significado extremamente intuitivo, porém, é importante situarmos o desenvolvimento desta habilidade no contexto da Matemática, pois, como afirmam Boavida et al

À primeira vista, pode parecer estranho falar em argumentação em Matemática, ou mais concretamente, falar em argumentação quando se trabalha em Matemática com os alunos. Afinal, no imaginário de muitos, a Matemática continua a ser uma disciplina em que os resultados a que se chega ou estão certos ou estão errados, consoante se siga, ou não, as indicações dadas pelo professor, pelo manual escolar ou por quem tem autoridade na matéria. Nesta concepção, não há grande lugar para atividades argumentativas, se as entendermos como experiências particulares de aprendizagem cujo foco é a Matemática e que assumem a forma de raciocínios destinados seja a fundamentar ideias associadas à exploração de tarefas matemáticas, seja a convencer alguém a aceitar ou a rejeitar enunciados ou posições pela indicação de razões (BOAVIDA et al, 2008, p. 81, grifo nosso). 
Referente à caracterização de "atividades argumentativas" apresentada por Boavida et al (2008), fica evidente a forma com a qual o desenvolvimento da argumentação matemática, surge, com destaque, no contexto de aula através da RP, em especial em dois momentos, no desenvolvimento das resoluções dentre os grupos, que requer que os alunos, ao socializarem ideias com os seus colegas, as justifiquem de forma clara e válida, e no momento de busca por consenso, em especial quando as resoluções diferem, já que os estudantes devem debater defendendo seus respectivos raciocínios. A evolução das capacidades de socialização se manifesta de forma intrínseca a estes momentos, sobretudo quando a proposta trabalha com grupos.

É claro, não se pode deixar de mencionar as capacidades de resolução de problemas, selecionar estratégias que, com base na dedução feita, permitam ao solucionador alcançar um resultado satisfatório. Estas capacidades são desenvolvidas de forma central na abordagem da RP, o aluno tem autonomia de selecionar e testar diferentes estratégias imagináveis, desenvolvendo gradualmente as habilidades referentes a este processo.

Resolver problemas é uma arte prática, como nadar, ou esquiar, ou tocar piano: você pode aprender somente através da imitação e prática. [...] se você deseja aprender a nadar você tem que entrar na água e se você deseja se tornar um bom solucionador de problemas você tem que solucionar problemas (POLYA, 1981, p. ix, tradução nossa).

É importante mencionar que a RP não se limita ao desenvolvimento destas capacidades, como Cai \& Lester (2010) afirmam, é possível delimitar ou estimular o desenvolvimento de diferentes habilidades através da Resolução de Problemas. No minicurso desenvolvido, por exemplo, foi possível observar como no 2..$^{\circ}$ encontro houve maior destaque nos quesitos interpretação de enunciados e argumentação matemática. Ao professor, aprender a coordenar estes aspectos no desenvolvimento dos problemas se torna uma competência fundamental na utilização da RP em sala de aula.

Delimitando o contexto de RP ao ensino de Análise Combinatória, destacamos que, o ensino deste conteúdo dado puramente através da aprendizagem de fórmulas e algoritmos é extremamente defasado, visto que a natureza da Análise Combinatória parte da contextualização e se desenvolve na mesma. Desta forma, a utilização da RP permitiu associar a contextualização requerida no processo de aprendizagem que incorporasse a compreensão contextual ao nível de generalização requerido pelo currículo no que se trata da Análise Combinatória.

Espera-se que as visões desenvolvidas e apresentadas no corpo desta pesquisa estimulem o professor em atuação a realizar reflexões em torno de sua atuação, reflexões estas que busquem aperfeiçoar o ambiente de prática docente através de ações metodológicas. A validez da proposta apresentada nesta pesquisa é fundamentada através de seus resultados, que evidenciaram os benefícios da utilização da Metodologia de EnsinoISSN 2526-2882 
aprendizagem-avaliação de Matemática através da Resolução de Problemas em se tratando da Análise Combinatória e, de forma recíproca, determinaram particularidades do ensino de Análise Combinatória através desta abordagem.

\section{Referências}

ALBUQUERQUE, C; VELOSO, E.; ROCHA, I.; SANTOS, L.; SERRAZINA,L.; NAPÓLES, S. A matemática na formação inicial de professores. Lisboa: APM, 2010.

ALLEVATO, N. S., ONUCHIC, L. R. Ensino-aprendizagem-avaliação de Matemática: por que através da resolução de problemas? In L. R. Onuchic, N. S. Allevato, F. C. Noguti, \& A. M. Justulin (Org.), Resolução de Problemas: teoria e prática (pp. 35-52). Jundiaí: Paco Editorial, 2014.

ALLEVATO, N. S.; VIEIRA, G. Do ensino de resolução de problemas abertos às investigações matemáticas: possibilidades para aprendizagem. Quadrante, 25(1), 113-131, 2016.

BOAVIDA, A. M. R; PAIVA, A. L.; CEBOLA, G.; VALE, I.; PIMENTEL, T. (Orgs.) A experiência matemática no ensino básico: programa de formação contínua em matemática para professores dos $10^{\circ}$ e $2 .^{\circ}$ ciclos. Lisboa: Ministério da Educação DGIDC, 2008.

BORBA, R. E. de S. R. O raciocínio combinatório na educação básica. In: Encontro Nacional de Educação Matemática, 10, 2010, Salvador. Anais... Salvador: SBEM, 2010.

BRASIL. Ministério da Educação. Secretaria de Educação Média e Tecnológica. Parâmetros curriculares nacionais para o ensino médio: ciências da natureza, matemática e suas tecnologias. Brasília: MEC/Semtec, 1999. $5^{8}$ p. - Ministério da Educação. Secretaria de Educação Média e Tecnológica. Parâmetros curriculares nacionais ( $1^{\mathrm{a}}$ a $4^{\mathrm{a}}$ séries): matemática. Brasília: MEC/Semtec, 1997. 142 p.

. Ministério da Educação. Secretaria de Educação Média e Tecnológica. PCN+ Ensino Médio: Orientações Educacionais complementares aos Parâmetros Curriculares Nacionais. Brasília: MEC/Semtec, 2002. 144 p.

. Ministério da Educação. Secretaria de Educação Média e Tecnológica. Parâmetros curriculares nacionais ( $5^{\mathrm{a}}$ a $8^{\mathrm{a}}$ séries): matemática. Brasília: MEC/Semtec, 1998. $148 \mathrm{p}$.

CAI, J.; LESTER, F. K. Why is Teaching With Problem Solving Important to Student Learning? Reston: NCTM, 2010.

GROENWALD, C.L.O.; ZOCH, L.N.; HOMA, A.I.R. Sequência Didática com Análise Combinatória no Padrão SCORM. Bolema, $n^{0}$ 34, ano 22, p. 27-56, 2009. 
KILPATRICK, J. Problem formulating: Where do good problems come from? In: SCHOENFELD, A. H. (Ed.) Cognitive science and mathematics education. Nova York: Routledge, 1987. p. 123-147.

KRANTZ, S. Discrete Mathematics DeMYSTiFieD. Nova York: McGraw-Hill, 2008.

MENEGHETTI, R. C. G.; DUTRA, A. C. B. Análise combinatória numa abordagem alternativa: análise de uma aplicação em um curso de Licenciatura em Matemática. Revista Quadrante, v. 21, n. 1, p. 67-94, 2012.

NATIONAL Council of Teachers of Mathematics (NCTM). Principles and Standards for School Mathematics. Reston: NCTM, 2000.

NUNES, C. B. A metodologia de ensino-aprendizagem-avaliação de matemática através da resolução de problemas: perspectivas à formação docente no contexto da sala de aula. In: REIS, M. J. E. et al. (Orgs.) Educação e Desenvolvimento: diferentes olhares. Coleção Formação e Práxis Docente, v. 2. Campinas: Pontes, 2015.

ONUCHIC, L. de la R. ; ALLEVATO, N. S. G. ; NOGUTI, F. C. H. ; JUSTULIN, A. M. (Orgs.) Resolução de problemas: teoria e prática. Jundiaí: Paco Editorial, 2014.

ONUCHIC, L. de la R.; ALLEVATO, N. S. G. Pesquisa em Resolução de Problemas: caminhos, avanços e novas perspectivas. BOLEMA - Boletim de Educação Matemática, Rio Claro: UNESP, v. 25, n. 41, p. 73-98, dez. 2011.

ONUCHIC, L. R. A resolução de problemas na educação matemática: onde estamos? E para onde iremos? Revista Espaço Pedagógico, Passo Fundo, v.20, n. 1, p. 88-104, jan./jun. 2013.

POLYA, G. Mathematical Discovery: on understanding, learning, and teaching problem solving. Nova York: John Wiley \& Sons, 1981.

ROSEN, K. H. Discrete mathematics and its applications. 6. ed. Nova York: McGraw-Hill, 2008.

SILVER, E. A., Acerca da Formulação de Problemas de Matemática. In: ABRANTES, P., LEAL, L. C., PONTE, J. P. (Eds.) Investigar para Aprender Matemática. Lisboa: Projecto MPT e APM, 1996. p. 139-162.

SOUZA, A. C. P. Análise combinatória no ensino médio apoiada na Metodologia de EnsinoAprendizagem-Avaliação de Matemática através da Resolução de Problemas. 2010. 343 f. Dissertação (Mestrado em Educação Matemática) - Instituto de Geociências e Ciências Exatas, Universidade Estadual Paulista Júlio de Mesquita Filho, Rio Claro, 2010.

VALE, I.; PIMENTEL, T. (Coords.) Padrões em Matemática: uma proposta didática no âmbito do novo programa para o ensino básico. 1. Ed. Lisboa: Texto Editores, 2011 


\section{Biografia Resumida}

Célia Barros Nunes - Licenciada em Ciências Matemática pela Universidade Estadual de Santa Cruz (UESC); Mestre em Matemática pela Matemática pela Universidade Federal da Bahia (UFBA); Doutora em Educação Matemática pelo Universidade Júlio de Mesquita Filho (UNESP - Rio Claro, SP). Pós-doutorado em Didática da Matemática pela Universidade de Lisboa. Professora Titular na Universidade do Estado da Bahia (UNEB - Campus X); Coordenadora do Curso de Especialização em Educação Matemática da UNEB/Cmpus X; Membro da diretoria da Sociedade Brasileira de Educação Matemática (SBEM - BA).

Link do Lattes: http://lattes.cnpq.br/5885292919107897

e-mail: cnunes@uneb.br

Thaylan Campeche Vidal -Licenciado em Matemática pela Universidade do Estado da Bahia (UNEB). Cursando Mestrado Profissional em Matemática pela Universidade Estadual de Santa Cruz (UESC). Professor do Quadro Temporário no Colégio Democrático Estadual Ruy Barbosa de Teixeira de Freitas.

Link do Lattes: http://lattes.cnpq.br/5031003397538335

e-mail: thaylancampeche@gmail.com 